\title{
Ancient Characters and Contemporary Readers: A Response to Elizabeth E. Shively \& Jan Rüggemeier and Cornelis Bennema
}

\author{
Suzanne Keen \\ Hamilton College, New York, USA \\ skeen@hamilton.edu
}

\begin{abstract}
In this response essay, which culminates with an application of my theory of narrative empathy to the Parable of the Good Samaritan, I comment on an article by Cornelis Bennema and engage with the ideas in the framing, introductory essay by Jan Rüggemeier and Elizabeth E. Shively. In the course of carrying out these tasks, I also offer what I hope will be broadly useful comments on fictional and nonfictional contexts for character construction, on characters and characterization, and on the way diverse actual readers engage with characters. This essay concludes with some thoughts on narrative empathy, responding to the final section of Rüggemeier and Shively's essay, which offers comprehensive overview of empathy and sympathy as aspects of emotional reading.
\end{abstract}

\section{Keywords}

lifewriting - narrative empathy - nonfiction - parable - referentiality

I dwell in the following pages not only on characters, characterization, and character identification, but on the way we think about what readers are doing when they respond to represented characters. In this I take up the challenge posed by Shively and Rüggemeier, when they write about formalist, structuralist, new historical, and poststructuralist theories' inadequacies with respect to reading: "Yet these movements are unable to explain how real readers decide what elements in a narrative are valid or relevant at all, how they use 
the extratextual information they access, or how they respond to characters on a mental and emotional level." Taxonomies of both readers and characters have constrained our thinking by bracketing out unruly responders and their creative imaginings. For if it is axiomatic that readers must use their imaginations to make inferences and fill gaps, it has been convenient for theorists to posit disciplined, well-read, knowledgeable individuals who look a lot like us as those readers. My response injects some skepticism into the conversation regarding generalizations made about readers' behavior.

\section{Response to "How Readers Reconstruct New Testament Characters: The Calling of Peter in the Gospels in Cognitive-Narratological Perspective"}

Cornelis Bennema draws attention to "the extent of the reader's knowledge in constructing characters," a maneuver that requires gap-filling inferences. ${ }^{2} \mathrm{He}$ capably calls up the relevant narrative theory and reception theory, augmenting these ideas with cognitivist theory by Ralf Schneider and Uri Margolin, both of whom contribute to our understanding of how humans' capacity for mental-modeling shapes character construction in reading. Whereas Bennema's earlier work systematically evaluated the available theories of character and touched more lightly on the reader's role, in this article he models different character-construction by sample readers with divergent textual and social knowledge. I admire the openness to multiple possible readers and reading experiences evinced in Bennema's contribution. It undertakes a highly useful exercise, one that focuses our attention on divergent readers, and extrapolates from their more replete or more limited knowledge a set of likely responses to the calling of Peter. Perhaps for the sake of streamlining an already complex argument, Bennema does not entertain the possibility that multiple individuals in the specific knowledge condition that defines each of his sample readers (Reader 1, Reader 2, and so forth) would themselves engage in different character construction as a result of their varied identities and experiences. I

1 J. Rüggemeier and E. Shively, "Introduction: Towards a Cognitive Theory of New Testament Characters: Methodology, Problems, and Desiderata," in J. Rüggemeier and E. Shively (eds.), Cognitive Linguistics and New Testament Narrative: Investigating Methodology through Characterization, Biblical Interpretation 4-5 (Brill, 2021), p. 405.

2 C. Bennema, "How Readers Construct New Testament Characters: The Calling of Peter in the Gospels in Cognitive-Narratological Perspective," in J. Rüggemeier and E. Shively (eds.), Cognitive Linguistics and New Testament Narrative: Investigating Methodology through Characterization, Biblical Interpretation 4-5 (Brill, 2021), p. 430. 
will elaborate on this point later. Bennema employs in his paper a reader he earlier defines as a "plausible historically informed modern reader," ${ }^{3}$ making quite clear that his brief is to imagine the character-construction of better or less well-informed modern readers, not first-century readers. This is reasonable, and I wholeheartedly agree with his conclusion that "interpreters should be more cognizant about their constructed reader because this will influence the reconstruction of characters." I certainly concur with Bennema that cognitive science encourages us to assume that "ancient and modern readers use similar cognitive processes in encountering a text," ${ }^{\prime \prime}$ but I especially appreciate the way he avoids flattening out the interpretive possibilities, which sometimes happens when cognitive processes are identified. We should avoid suggesting that the possession of a cerebral cortex and literacy leads inevitably to the exercise of the same cognitive operations, arriving at identical understandings and empathetic responses. Bennema's nuanced thought experiment leads in the opposite direction, towards character-constructions of divergent specificity and quality.

I propose to engage with the problem of the reader and his or her character-construction first by discussing the understanding of character in nonfiction. Bennema provides extra-textual knowledge to his imagined sample readers, writing "readers should go beyond the text when it concerns the reconstruction of New Testament characters and fill the textual gaps from their knowledge of the socio-cultural context of the first-century Mediterranean world (rather than from unregulated imagination)." ${ }^{6}$ This is a justified extension beyond the New Critical restraint to the text itself, considering that, in Bennema's words, "many scholars regard the narrative material of the New Testament as nonfictional and as having some referential relationship to real events and people in history." ${ }^{7}$ We will be returning to the problem of the reader's imagination which is in my view inseparable from human cognition. First, let me immediately acknowledge a sticky wicket: with very modest exceptions, my expertise is in narrative fiction, not nonfiction narrative. That's true of a lot of narrative theory, despite the fact that narrative itself encompasses both modes. Yet the way we narrative theorists think about character and characterization is at

3 C. Bennema, A Theory of Character in New Testament Narrative (Minneapolis, Fortress Press, 2014), pp. $67-72$.

4 C. Bennema, "How Readers Construct," p. 450.

5 C. Bennema, "How Readers Construct," p. 432 n6.

6 C. Bennema, "How Readers Construct," p. 437.

7 C. Bennema, "How Readers Construct," p. 437. 
least complicated by the fictional or nonfictional presentation of represented persons.

The response to nonfiction involves the possibility of external verification or contradiction. There are only vanishingly small differences of technique between the narrative form of fiction and the narrative form of non-fiction lifewriting such as the gospels (or Greco-Roman lifewriting), but the difference of referentiality distinguishes nonfiction from fiction. Referentiality does not require first-hand witnessing on the part of readers or auditors to activate its aura of facticity. It can be vouched for by second- or third-hand reports, by official records, by family lore, or by the belief on the part of the audience that these verifications exist. Referentiality would be especially pertinent to the very first readers and auditors of gospel narratives. They would not have to have coexisted with the characters of the narratives to feel that referentiality to the real. Even setting aside the reputation of oral cultures in late antiquity for long preservation of knowledge about persons, even now an aura of facticity clings to stories about the long departed, within families and communities. People often vouch for facts and tales about family members four generations back, whose lifespans occurred fifty to eighty years earlier than their own births. The earliest audiences or readers of the gospels would be able to recognize the names of real persons (and maybe even know who they were related to or where they lived) and to distinguish them both from composite characters representing culturally plausible types of individuals, and from supernatural beings such as angels and demons. I acknowledge that the location of the boundary between fiction and nonfiction has been highly variable over the centuries, and that the gospel's "good news" nonfiction includes a generic admixture of wonder stories. Yet I am convinced that readers' perceptions of whether they are engaging with a "real" or "historical" narrative (as opposed to something belonging to the realm of make-believe) profoundly impacts their responses, including their character construction and their responses to characters. Even without speculating about first-century readers, we can see those differences in the gospel texts themselves.

Though the gospels take the form of nonfiction narrative, they also contain embedded fictional narratives, and they thus invite different kinds of character construction (with or without external validation) depending on the narrative level. We can mark this difference inside the gospels, because Jesus, beyond his role as protagonist, is also a secondary narrator who tells parables. The way the disciples and other audiences (Pharisees, tax-collectors) respond to the parables does not focus on the identity of the characters in the real world (referentiality). The genre of parable signals exemplarity and points to the drawing of a moral or lesson. Those first auditors of Jesus grasp that the parable-characters 
are defined by what they stand for: a layer of meaning, either hard to get at or readily interpreted, ${ }^{8}$ but in any case encoded in brief narratives that are understood to be metaphorical. We don't see the disciples saying, "Oh yes, the prodigal son; he was my friend's cousin," or "That's not what I heard about his return." The parable characters differ markedly from the narration's introduction of persons in the primary narrative realm, the life world, of the synoptic gospels. Parable characters are simple fictional figures whose situations set up messages: a noble man entrusts his servants with money while he goes on a long journey; an unjust judge deals with a persistent widow; a man plants a vineyard and lets it out to vine-growers, then bad tenants kill the son and heir sent as a messenger. Auditors such as the scribes and priests recognize the threat in the depiction of the bad tenants; they know that the parable disguises a pointed message, not really about real estate and rent collection, and they respond accordingly. In contrast, the nonfictional frames of the synoptic gospels use characters to locate the narrative that follows in the real world. Matthew opens with a genealogy full of names; Mark introduces the prophet John the Baptist; Luke opens with a historical setting and characters specified by their professions and ancestry (Herod, Zechariah, Elizabeth). These gestures activate referentiality by setting up the potential for verification: even if the reader isn't in the position to certify the assertions, the formulaic expressions of facticity invoke a nonfictional contract. These persons are thus all understood to be real individuals of the narrative world, connecting the characters of the New Testament narratives to Hebrew Bible individuals, a celebrity prophet, and a Roman client-king. When it comes to the less famous but more important characters of the gospel narratives, such as the disciples, they are very often introduced by both location and relationship: James and John, for example, are the sons of the Galilean fisherman Zebedee. These represented persons become active agents of the primary narrative. The historicity of these primary world characters is projected by the nonfictional frame, which provides the kind of information that suggests that their existence or identity could be verified.

The most important difference between fictional and nonfictional representation is that the former can never be contradicted, while the latter can be falsified: as Sir Philip Sidney writes in The Defense of Poesie (1595), "the Poet, he nothing affirms, and therefore never lieth. For, as I take it, to lie, is to affirme that to be true, which is false." ${ }^{\prime 9}$ Nonfiction narration can be contradicted, either

8 On hina and hoti, see F. Kermode, The Genesis of Secrecy: On the Interpretation of Narrative (Cambridge: Harvard University Press, 1979), pp. 32-34.

9 P. Sidney, The Defense of Poesie (Oxford: Oxford University Press, 1974), p. $5^{2}$. 
by people with first-hand knowledge or access to records, or by interested parties with alternative interpretations. My point is not that contests about the interpretation of nonfiction narrative can be more easily settled, rather that arguments about the meanings of fictional representations can never be settled by reference to an external reality. The parable characters are fictional characters, presented within a nonfictional frame that asserts the bona fides of the narrator to relate authentic knowledge of events that took place among a community of people made up of eyewitnesses (Luke 1:1-4). That Jesus told parables is a fact of the gospels, in a nonfictional generic sense. Other facts of the gospels include the existence of Herod and John the Baptist. But the man traveling from Jerusalem to Jericho who is set upon by robbers? The priest, the Levite, and the Good Samaritan? These characters in an inset tale, narrated by Jesus, can be regarded as illustrative fictional beings who exist to set up the teacher's prompt: "Which of these three do you think was the neighbor to the man who fell into the hands of the robbers?" (Luke 10:36). Whether parables are told to conceal or reveal meaning, they are clearly fictions to be decoded by the listeners of the primary narrative world.

More problematic are characters whose presence violates the ontological boundary between natural and supernatural realms. What do we do with the character of Legion, who speaks through a possessed man, with the demon voices and actions of demoniacs, with the devil who tempts Jesus in the wilderness, with the angel Gabriel? These agents and actions are located squarely in the primary narrative level of the gospel texts where they appear, presented as interlocutors of Jesus or his mother. The demoniacs can be explained naturalistically. Yet arguably, even for the original readers and auditors of the gospel narratives, the supernatural voices signal a different generic register than the actions and speech of other characters of Jesus's life-world. Tackling the ontological problems brings us swiftly to epistemological problems: how would we ever know how ancient auditors and readers understood the boundaries between the real and the imaginary? What textual cues spur them to see characters illustratively, symbolically, or to validate reality claims? Richard Gerrig has persuasively argued that human beings have a strong preset towards believing in the veracity of stories; disbelief has to be constructed..$^{10}$ The location of supernatural characters within the primary narrative level that also contains historical or verifiable characters suggests that these persons would have been accepted as part of the real story in a way that differs from the Good Samaritan

10 R. Gerrig and B. Pillow, "A developmental perspective on the construction of disbelief," in J. de Rivera and T. Sarbin (eds.), Believed-in Imaginings: The Narrative Construction of Reality (American Psychological Association, 1998), pp. 101-119 (103-104). 
or the Prodigal Son, who are clearly fictional characters. To put it another way, in terms of the nonfictional narrative contract, both the Angel Gabriel and Joseph of Arimathaea demand to be read as real in a way that the rich man Dives does not. So, following Gerrig, I effectively reverse the postmodern contention that narrativizing is a mechanism of fictionalizing. Narrativizing in a nonfiction storyworld like the gospels harnesses the human preset to believe in veracity, rendering even manifestly impossible characters as real. This of course includes the protagonist of the gospels, whose life, works, teaching, and death on the cross is their central subject. But I do wonder about the opening of John's gospel. Is the Word a New Testament character? It is certainly an actant, in a Greimasian sense, with the abstract power of a subject and the motive force of a sender. ${ }^{11}$

\section{Response to "Introduction: Towards a Cognitive Theory of New Testament Methodology, Problems, and Desiderata."}

Our conveners Jan Rüggemeier and Elizabeth Shively have focused our attention on "four aspects of character analysis that seem particularly promising for New Testament exegesis: characterization, character development, character migration, and character emotions,"12 acknowledging that the relation of character to meaning, genre, plot, and movement and space also deserve critical scrutiny. Shively and Rüggemeier draw on John Darr's cognitive understanding of characterization, quite rightly to assert that "characters are not simply "in' the text; rather, characters are both communicated and constructed."13 This points towards the impact of the reader, about which so little is known, and whose actions are so powerful. Rüggemeier and Shively address the situation plainly, acknowledging the necessity of a historical exegesis to temper the influence of modern knowledge on the reading of ancient characters: "yet even attention to characters as a historically informed paradigm of traits tends to focus on formal elements without accounting for the variety of human-like properties (i.e., mental, physiological, emotional, spatial) by which various readers understand and respond to characters, or for how readers respond to

11 A. J. Greimas, "Actants, Actors, and Figures," in On Meaning: Selected Writings in Semiotic Theory, trans. P. Perron and F. Collins (Minneapolis: University of Minnesota Press, 1987), pp. 106-120 (106-109).

12 J. Rüggemeier and E. Shively, "Introduction," pp. 427-428.

13 J. Rüggemeier and E. Shively, "Introduction," p. 406, emphasis in original. 
characters at all."14 I profoundly agree with their criticism of habitual privileging of the implied author or narrator's contribution to characterization, for creating a "disembodied reading process that does not fully account for the role of real authors and real readers in character construction."15 One of the benefits of a cognitive approach is pulling human beings back into our theorizing, even if much cognitive criticism is resolutely textual. My starting point in this response will be to discuss the difference between real or actual readers and authors and their implied counterparts.

Shively and Rüggemeier employ the narrative communication model developed by Wayne Booth and popularized by Seymour Chatman. My own congruent sense of readers' strong involvement in imaginative constructive work derives from early reception theory by Louise Rosenblatt ${ }^{16}$ that embedded a notion of co-creation in what was later developed by Booth, Chatman, Prince and Rabinowitz ${ }^{17}$ into a rhetorical model of communication that runs from actual readers and implied readers, to narratees and the represented beings (characters) of the storyworld, narrators, all the way to implied authors and actual authors. In the case of biblical narrative, we are aware of the difference between the implied author "Luke," physician and companion of Paul, and the actual author, likely an anonymous Christian scribe and narrative artist, probably not the physician Luke. Even if the actual physician Luke truly wrote the words of Luke's gospel and Acts, he left behind an implied author called Luke, who started as an embodied person, but who exists perpetually in the present tense for generations of readers, extending on from the biological literate person who put the memories and traditions together for Theophilus. This difference between implied and actual authors need not trouble us: I mention it because it is widely accepted. The actual author had a life; the implied author lives on, as a projection of the text. I find it useful to think of the "Luke of the Gospel of Luke" and the "Luke of Acts" as two distinct implied authors, both probably emanating from the same actual person of the first century Hellenic world. At least in literary studies, it is these implied authors who receive verbs in the present tense when we write about their authorial actions, whereas the

\footnotetext{
14 J. Rüggemeier and E. Shively, "Introduction," p. 410.

15 J. Rüggemeier and E. Shively, "Introduction," p. 410, emphasis in original.

16 L. Rosenblatt, Literature as Exploration (New York: Appleton, 1938).

17 W. Booth, The Rhetoric of Fiction (Chicago: University of Chicago Press, 2nd edn, 1983), pp. 428-431; G. Prince, A Dictionary of Narratology (Lincoln: University of Nebraska Press, 1987), pp. 42-43, 57. S. Chatman, Story and Discourse: Narrative Structure in Fiction and Film (Ithaca: Cornell University Press, 1978), p. 151; P. Rabinowitz, "Truth in Fiction: A Reexamination of Audiences," Critical Inquiry 4.1 (Autumn, 1977): pp. 121-141.
} 
actual author (if known) is a historical person whose life, work, and death receives past tense verbs.

But what of readers? Peter J. Rabinowitz develops the idea of narrative and authorial audiences with respect to fiction, yet one can apply the willing credulousness of a narrative audience to categorize readers, ancient or modern, who respond to the gospel narratives as nonfiction. The narrative audience, following Rabinowitz, offers an observer-position for readers who have accepted the text's claims as real. ${ }^{18}$ One might say that the evocation of a believing narrative audience is a test of the gospel narratives' putative nonfictionality. The implied readership, in contrast, describes the specific audience projected by the text, as reflected in textual cues. In the case of Luke's gospel, the implied audience would be the narratee Theophilus and possibly Roman officialdom, Theophilus' community, other Gentile Christians, and a posterity interested in Luke's orderly narrative. Rabinowitz's authorial reader is an actual reader who actively works to achieve entry into the implied readership by living up to the expectations projected by the text. I emphasize a volitional effort on the part of actual readers to live up to the text's expectations for implied readers by becoming a part of the authorial audience. If they succeed (perhaps they would have to be Christian believers to do so), these authorial readers could also join the narrative audience, accepting without difficulty miracles, the casting out of demons, and conversations with angels and the devil. In my use of Rabinowitz's terms, the decision made by actual readers to work harder to overcome those differences shows an interest in joining the authorial audience, but certain components of belief might be required to become a narrative audience member. An actual reader's audience membership would certainly have a bearing on character-construction, interpretation, and response, so these terms and categories matter to the work at hand.

The gap between the authorial audience and actual readers today can be bridged but not closed. The millennia of continuity in reading New Testament narratives cannot eradicate the chasm that yawns between us and the gospels' first readers and auditors. In the case of Luke's gospel, the implied readers include Theophilus (who is also the narratee), the early Christians who contributed to the author's investigations, new Christian communities in the Roman world, and also generations in posterity, who did not have the privilege of knowing Jesus and the apostles or Paul. You might say that all of us are swept in under the generations of posterity, but we must acknowledge straightaway that we can never be part of the original authorial audience, and not all will have read with the intention of becoming an authentic member 
of the narrative audience, taking the characters and events as true, and reading the narrative as history. While many actual readers have taken that literal approach to gospel narratives, their responses to the characters of the gospels likely differ from those other contemporaries who read with literary lenses.

This response affords me the opportunity to add some thoughts about audiences and readers, about which I signal two difficulties in my subtitle, "Ancient characters and contemporary readers." The word "contemporary" I deliberately use in an ambiguous fashion, alluding to two distinct conditions. The readers and auditors who were contemporary with the gospel authors are for the most part elusive to us. I acknowledge important exceptions. 1) We can learn something about ancient readers who become writers themselves. 2) We can extrapolate something about the concerns and needs of communities of readers from the New Testament texts directed towards them, perhaps especially in the epistles. Associating a gospel narrative (or Acts of the Apostles) with a community means that we should imagine the possibility that the community had possession of knowledge about events of their parents' or grandparents' time, and that individuals might carry the memory of lives preceding theirs by several generations. (I know quite a lot about the nineteenth-century lives of my great-great grandparents, whom I never met, but about whom I heard from my own grandparents.) This situation, in nonfiction narration, exerts some degree of pressure on an author, promoting, though not assuring, accuracy. Of course, it also might impel an author to spin representations in a way that decreases accuracy, to suit the wishes, beliefs, or prejudices of the community audience. This angle may seem to give too much power to the original, contemporary audience, who lived at the same time as the gospel authors. But at least some of those original readers did have a more immediate access to critical impact: they could talk back to the authors, correct, embellish, advocate, and pose questions. I assume that they did so.

The second meaning of "contemporary" readers from my subtitle points to us, thousands of years distant from the original authors and millions more numerous. We cannot talk back to the original authors, and although we may correct, embellish, advocate, and pose questions, our audience must be other distant readers now and in the future. Our only hope of influencing the text created by the gospel authors is through translation or critical editions. (I set aside creative endeavors such as novels or films.) We must content ourselves with the communication of, and arguments about, interpretations. We lack the ability to contradict the assertions of the gospel texts to its writers, but we can still attempt to recover as much as possible about ancient contexts to understand the gospels better and to supply illuminating background. This could make us into what Bennema calls the "plausible historically informed modern 
reader."19 I am sure that I am not alone in poring over the discoveries of biblical archaeology with avid interest. But I have to insist that many, if not most, actual contemporary readers do not make the effort to become plausible historically informed modern readers of the gospels. Many practicing Christians content themselves with the snippet views presented within the liturgy. We and other living readers of New Testament narratives are almost inconceivably diverse in terms of what we bring to the reading process, including the work of character construction. Nonetheless, it's worth pondering what these two senses of contemporary readerships have in common. Here interdisciplinary awareness of brain science can assist. We share with our ancient precursors human endowments - cognitive and affective capabilities, biological substrates supporting intersubjectivity, language, and mortality. Like them, we are profoundly shaped by family, education, culture, and the historical events that precede our political realities. Like them, we perceive differences among other people and we understand our own identities at least in part in relation to those differences. Like them, we are imaginative co-creators of the stories and characters that we read, watch, or hear. Generalizing about the reading and responses of actual individuals so numerous and so diverse might seem an absurd project, but strategies offered by cognitive narratology and the study of literary universals do provide angles of approach.

The usual tactic is to ignore or even erase the actual readers because their overwhelming number and staggering differences are too daunting to deal with. The exception to this rule is the case of the actual reader who becomes a writer/interpreter in his or her own right: we can read over the shoulders of Augustine or Julian and we can glimpse something about their reading practice as well as their theology. Despite the difficulties involved in thinking about actual readers, I want to hang onto them. I want to hold out for our consideration the differences that emerge among even a small gathering of students with a lot in common. Every classroom teacher who allows discussion rather than lecturing the whole time knows this. Not only can we not make ourselves into ancient readers, but we cannot even make ourselves into accurate predictors of how other contemporary readers who share time, place, culture, education and many other traits with us will respond to characters. Lectures, sermons, homilies, not to mention visual depictions, may attempt to channel into uniformity a group's response to a narrative, but the unruliness of interpretation flows from a wellspring that cannot be dammed up. That wellspring is the imaginative co-creation that comes from readers and their imaginations. Louise Rosenblatt theorized the role of the reader as co-creator, 
writing "a text, once it leaves its author's hands, is simply paper and ink until a reader evokes from it a literary work." ${ }^{20}$ Text and reader are dynamically interfused, ${ }^{21}$ and while texts offer both openness and constraint, ${ }^{22}$ readers possess particular attributes that make their contributions unique. ${ }^{23}$ Each co-creating reader brings in an individual imagination, shaped by memories of particular experiences, to the task of co-creation. There is no wishing away readers' imaginations. Readers can no more turn off the confabulating features of their cognition than they can stop understanding the written word once they have attained literacy.

Readers' imaginations and responses are bound up with their intersectional identities. In addition to multiple competing axes of identity, ${ }^{24}$ readers' distinct cultural contexts, differing personal qualities, and unique experiences all shape their co-creation of the narratives that they read. ${ }^{25}$ These identities, along with differences of experience and context, change the materials that they contribute to character co-creation. In my view these differences layer upon and can override the basic human similarities upon which the claims of cognitivism rest. Although psychological science has documented ranges of responses to narrative stimuli, with more and less common responses elicited by scales or measures of intensity, it does not countenance assuming predictable responses to narrative representations either by individual readers or by reader category. In thinking about how diverse readers respond to characters and characterization, I am resolutely not offering a model of how they respond to narrative cues, beyond engaging (variously) in gap-filling imagining. I follow Meir Sternberg in affirming that no one narrative technique consistently evokes a single predictable response, embracing instead his "Proteus Principle": the "many-to-many correspondence between linguistic form and representational function." ${ }^{26}$ Divergent responses to emotionally evocative narrative can be better understood if readers can be posited as diverse. However, reader

20 L. Rosenblatt, The Reader, the Text, the Poem (Carbondale and London: Southern Illinois University Press, 1978), p. ix.

21 L. Rosenblatt, Reader, p. viii.

22 L. Rosenblatt, Reader, p. x.

23 L. Rosenblatt, Reader, p. 15.

24 K. Crenshaw, "Mapping the Margins: Intersectionality, Identity Politics, and Violence against Women of Color," Stanford Law Review 43.6 (1991), pp. 1241-1299.

25 S. Keen, "Intersectional Narratology: Queer, Feminist, Cognitive, and Affective Crossings," in R. Warhol and S. Lanser (eds.), Narrative Theory Unbound: Queer and Feminist Interventions (Columbus: Ohio State University Press, 2015), pp. 123-146.

26 M. Sternberg, "Proteus in Quotation-Land: Mimesis and the Forms of Reported Discourse," Poetics Today 3.2 (1982), pp. 107-156 (112). 
diversity poses a challenge for determinations about the results, in real readers, of potentially emotionally evocative narratives.

Despite my wariness about assigning set relationships between and among narrative techniques, representations, and readers' responses, I will nonetheless explore in this brief conclusion a strategy of empathetic representation (used by authors to move readers) that may come in useful as we try to discern the craft of ancient authors through our distanced readings and responses. Broadcast strategic narrative empathy ${ }^{27}$ may play a role in the enduring appeal of some (but not all) New Testament characters. The beaten robbery-victim, left for dead by the side of the road in the Parable of the Good Samaritan, makes a good example of a character whose represented situation has evoked empathetic readings from diverse readers over millennia. Indeed, as Bonnie Howe and Eve Sweetser observe, transcultural ground supplements common ground, enabling recognition: "modern readers share considerable common Ground with ancient characters: we know what it is to travel down a road, to be wounded, to encounter a needy stranger."28 Fotis Jannidis's discussion of the relation between character and reader emphasizes three elements that bear upon narrative empathy and help us gain purchase on empathetic characterization in a New Testament narrative.

Fotis Jannidis writes:

For most readers, characters are one of the most important aspects of a narrative. How readers relate to a character is a matter of empirical analysis, but it is important to bear in mind that the way the text presents a character is highly influential on the relation between character and reader. Three factors in particular are relevant in this regard: (a) the transfer of perspective; (b) the reader's affective predisposition toward the character-itself influenced by: (i) the character's emotions, whether explicitly described or implicitly conveyed; (ii) the reader's reaction to her mental simulation of the character's position; (iii) the expression of emotions in the presentation - and (c) evaluation of characters in the text. ${ }^{29}$

27 S. Keen, Empathy and the Novel (Oxford and New York: Oxford University Press, 2007), p. xiv; "Strategic Empathizing: Techniques of Bounded, Ambassadorial, and Broadcast Narrative Empathy," Deutsche Vierteljahrs Schrift 82.3 (Sept. 2008), pp. 477-493.

28 B. Howe and E. Sweetser, "Compassionate Samaritan," in J. Rüggemeier and E. Shively (eds.), Cognitive Linguistics and New Testament Narrative: Investigating Methodology through Characterization, Biblical Interpretation 4-5 (Brill, 2021), p. 471.

29 F. Jannidis, "Character," in P. Hühn, et. al. (ed.), Handbook of Narratology 1 (Berlin: De Gruyter, 2014), pp. 31-32. 
Proceeding systematically, is there a transfer of perspective to the beaten man? Yes: he is an object of external focalization as he travels, is set upon, robbed, beaten and left half-dead. Then, what might the reader's predispositions be? Most readers, perhaps excepting violent thugs, would naturally align their sympathies with the robbery victim. The centering of the victim's experience assures this; empathy or pity for the human or animal objects of cruelty or violence (when the victim is not at fault) is one of the most consistent responses in the area of narrative empathy.

More complex mental simulation is invited by the introduction of additional characters. The victim's emotions are not mentioned, but they are implied, especially as the sequence of non-helpers arrive on the scene and decline to involve themselves in rescuing the victim. Here we may infer that a likely universal pity for the victim gets complicated by the different dispositions and experiences of readers mentally simulating the priest's scooting by and the Levite's avoidance of the prone body. Potential responses to these circumstances do not all point in the same direction. Despite moral imperatives to help people in need, not every reader is a natural altruist. Some will have experienced frightening circumstances that have prompted hiding, hurrying by, or ignoring appeals for help in real life. The mixture of reader emotions thus diversifies, until the relief and admiration elicited by the actions of the Good Samaritan, the true neighbor of the parable, returns most readers to a shared emotion that is underscored by strong closure: he even pays the bill at the inn. Jannidis emphasizes the importance of the expression of emotion in the presentation, so it's important to note that the one and only directly recorded emotion in the parable is attributed to the Samaritan, when he takes pity on the victim. The parable ends with Jesus's teacherly moral prompt to evaluate the characters by their behavior: which of the three do you think was a neighbor? (Luke 10:25-37).

The narrative empathy evoked for the robbery victim of the parable does not require contextual knowledge or good moral character of the reader. In this respect, the broadcast narrative empathy still works for posterity audiences long after Luke wrote down Jesus's parable. However, the certainties falter once we move away from the character of the victim. Recapturing the sense of shock that it is the Samaritan who deserves approbation as the one who shows mercy, acts altruistically, rescues the beaten man left for dead, and pays for his care after tending his wounds: that requires intervention. I wager that the Good Samaritan may be the New Testament character whose characterization fails most dramatically with modern readers, even as we are exhorted to become Samaritan helpers ourselves. I have heard countless homilies and sermons attempt to ramp up the emotional impact of the parable by reinjecting 
context: specifically, the tribal disgust at a member of a despised outgroup that Jesus leverages to defamiliarize the label "neighbor."

The irony of the Samaritan's goodness is invested wholly in the valences of the label "Samaritan." Twenty-first century actual readers don't shudder at the thought of $a$ Samaritan touching or bandaging a wounded body. Unprepared by prejudice, we read his actions with approval, without the contradictory frisson of contact with an unclean enemy. Indeed, the epithet most associated with the character of the Samaritan is "Good." We have to be taught to understand that "Good" to mean "The shockingly good example of a normally wretched type of person." Lacking that specific prejudice, it's difficult to acquire it, especially since every single depicted action of the Samaritan is in fact, good.

The narratee (the expert in law) and the implied reader are clearly meant to feel the sting in Jesus's rewriting of the definition of neighbor: a good neighbor acts mercifully, despite your low opinion of his community. Furthermore, the probably Jewish brigands and respected members of one's own community flagrantly fail the test. If I were writing a theory of character and characterization in New Testament narrative, I would begin by probing the waning power of ethnic slurs that have lost their emotionally evocative force as metonymies of otherness. Since humans have not shed their prejudices against despised minorities in the millennia that have passed, I put it down to altered contexts that have made the dream of achieving fusion with either the authorial or narrative audience of the gospels an unrealizable goal, even with the insights of cognitive science. So I would plump for "plausible historically informed modern reader[s]," acknowledging their imaginative co-creative role, and recognizing that they - we - are legion. 